
\title{
28 Research Suare \\ Depression, Anxiety, Stress, and Resiliency in Iranian Families with Autistic Children
}

\author{
Maryam alsadat Hosseini \\ Iran University of Medical Sciences \\ Fatemeh Shirzad \\ Iran University of Medical Sciences School of Behavioral Sciences and Mental Health \\ Masoud Ahmadzad-Asl \\ Iran University of Medical Sciences \\ Fatemeh Hadi ( $\nabla$ hadi.f@iums.ac.ir) \\ https://orcid.org/0000-0002-0893-8699
}

Research article

Keywords: family resilience, depression, anxiety, stress, autism

Posted Date: July 20th, 2020

DOI: https://doi.org/10.21203/rs.3.rs-42252/v1

License: (c) (i) This work is licensed under a Creative Commons Attribution 4.0 International License. Read Full License 


\section{Abstract \\ Background}

Autism is a chronic, debilitating condition that begins in childhood and is associated with burnout and sometimes even depression and anxiety in families. The main objective of this study was to investigate the relationship between resilience and anxiety-depression-stress among families of children with autism in 2018.

\section{Materials and Methods}

In this cross-sectional study, after the Ethics Committee approval, according to the calculated sample size, 137 members of the families of children with autism were selected randomly. They were selfquestioned themselves by family resilience scale, and also DASS-21 questionnaires, along with the checklist of variables such as number of family members, marital status, educational level, income, background of physical and mental disorders, age and sex. After data collection, they were entered into and analyzed by MS Excel and SPSS V.24 software.

\section{Results}

The mean age of the subjects was 40.67 years $( \pm 9.12)$ with the range of 42 years. 80 persons $(58.4 \%)$ were female and $57(41.6 \%)$ were male, most of who had a bachelor's degree (51.7\%), and generally were married (78.8\%) (Living with family). They often had a history of chronic physical (84.7\%) or mental illness $(95.6 \%)$. The mean of the family resilience scores was $193( \pm 25)$ and its range was 124 . There was no significant correlation between age/gender and resilience, but depression, anxiety and stress were related to the level of resiliency. Regarding the rate of depression, $51.8 \%$ were normal, $10.2 \%$ had mild depression, $22.6 \%$ had moderate depression, $10.2 \%$ had severe depression and $5.1 \%$ had very severe depression; income and history of mental illness were significantly associated with depression. In addition, the level of anxiety was $46 \%$ normal, $8 \%$ mild, $17.5 \%$ moderate, $11.7 \%$ severe and $16.8 \%$ very severe. The number of family members, educational level, income, and history of mental illness had a significant effect on people's anxiety. Also, the stress status of the studied samples were $43.8 \%, 12.4 \%$, $26.3 \%, 10.9 \%$ and $6.6 \%$ normal, mild, moderate, severe and very severe, respectively. The level of education, income, history of mental illness and gender were statistically significant with the level of stress among individuals.

\section{Conclusion}

Based on the results of this study, it is concluded that family resilience is a factor that directly correlates with the level of depression, anxiety and stress among the family members of the autistic children. It is 
therefore advisable to increase this ability of individuals in various ways, such as training, counseling, support groups, and etc.

\section{Introduction:}

During recent decades, resiliency is considered one of the components of a person's ability to cope with mishaps and hard days of life. Resiliency is the process of persons' empowerment during stressful situations; Therefore, in most cases, preventing negative behavior and thinking. Which would result in positive outcomes despite everything[1]. It is also known as a protective factor in the science of behavior. Individuals, with resilience ability, will often return to their normal behavior after such a pressurizing situation [2]. This concept also applies to family, which is defined as the ability of families to return from crises[3]. To understand the basic concept of resilience in the sense of this issue, resilience is the reason why some families ruin in the face of disasters such as the illness, disability, or the loss of family members, but others adapt to the new circumstances[4].

From the systemic perspective, a person's illness/disability has an impact on the whole family and could turn the course of events and decisions over time[5]. One of these conditions is autism, a disorder characterized by repetitive restricted behaviors and deficits in communication and social skills. Symptoms, based on diagnostic criteria of DSM V, are deficits in social interaction, and communication skills, and restricted behavior, movements, and interests[6]. Even a few months after birth, they have faint eye contact or avoid it. They don't want to be hugged, kissed, or caressed by family members. Sometimes some of them do not experience separation anxiety in unfamiliar environments, and social cues such as a smile, a handshake, or a wink are meaningless for them [7].

In general terms, social interactions, and the ability to interact with others are not their strong suit. Due to social immaturity, they are not able to make and sustain friendships. At puberty, they have sexual desires but lack the social skills to develop into sexual relations. Also, the failure of mimicking the behaviors of others is seen in the majority of these children[8]. So, their families are under challenging circumstances, and mental pressure and anxiety caused by having children with disabilities $[9,10]$. Mothers of these children experience much higher concerns in a chronic way, which could lead to depression in the longterm[11]. This state of depression and anxiety can reduce the mental health of parents, which can lead to ineffective family functioning $[12,13]$. One of the acquired psychological characteristics that can reduce family anxiety is Resiliency. Given the importance of the role of resilience as protective factors in living conditions of families with autistic children against depression, and anxiety, knowing their psychological conditions can play an important role in improving their quality of life. So we decided to examine the resilience of families with autistic children and study its relationship with anxiety, depression, and stress.

\section{Materials And Methods:}

This is an analytical cross-sectional study, that was done between September to November 2018. Our study population was the parents of students with autism who were studying in a special school for 
these children. The criteria for entering this study was considered 1) Announcement of consent to participate in this research 2) Parents or family members of children with autism who was responsible for their care. After the Ethics Committee approval, according to the calculated sample size, 137 members of the families of children with autism were selected. Due to the possibility of non-cooperation of some parents, 160 cases were extracted. The children's files were selected from the files in the school by simple random sampling. Their parents were contacted and asked to participate in our research. Checking variables were age, sex, resilience Score, number of family members, marital status, educational status, income, history of mental and physical illnesses, and anxiety, depression, and stress scores. Participants completed three questionnaires in one session

Measures:

"Family Resiliency Scale":

This scale was used to assess family resilience. It has three main domains, including: family belief system, family organization system, and problem-solving processes. This questionnaire has 66 questions. Each question could be scored from 1 (lowest) to 4 (highest) ..Its reference range is from 66 to 264; the higher the score, the more family resilience.

"Family Resiliency Scale" developed in 2005 based on Walsh's theory. And the psychometric evidence was confirmed by Sixbey. Reliability of this scale using Cronbach's alpha method and its validity using construct validity, Predictive and concurrent criterion validity has confirmed.[14] The Persian version was evaluated by Dr. Dadashi and colleagues in a research correlational study. After preparing a questionnaire according to Iranian society with both exploratory and confirmatory methods, its validity was confirmed by the principal component method and its reliability was confirmed by Cornbrash's alpha method.[15]

DASS-21 questionnaire: this questioner evaluates three domains, including anxiety, stress, and depression. The original version has 42 questions, but because in this study resilience questionnaire was also used, the shortened version with 21 questions was selected to accelerate the data collection process. Each domain contains 7 questions, which could be scored from 0 (never), 1 (slightly), 2 (sometimes), and 3 (Always) [16]. Since this questionnaire is a shortened form of scales (42 questions), the final score of each subscale must be doubled. According to the following scales, the status of each subscale is as follows: 
Table 1

Scoring scales of DASS

\begin{tabular}{|llll|}
\hline severity & depression & anxiety & stress \\
\hline normal & $0-9$ & $0-7$ & $0-14$ \\
\hline mild & $10-13$ & $8-9$ & $15-18$ \\
\hline moderate & $14-20$ & $10-14$ & $19-25$ \\
\hline sever & $21-27$ & $15-19$ & $26-33$ \\
\hline very sever & $27<$ & $19<$ & $33<$ \\
\hline
\end{tabular}

\section{Data analysis:}

After data collection, they were entered into and analyzed by SPSS V.24 software. The significance level ( $P$ Value) was considered less than 0.05 . In the descriptive analysis of the results, the frequency and percentage and central indices of mode and mean and the index of distribution of standard deviation and range were used. To analyze data from single-variable analysis methods such as chi-square test and independent T-test and two variables

\section{Results:}

In this study, a total of 137 members of the families of custody of the children with autism studied in 2018. $80(58.4 \%)$ of people in the study were female, and 57 (41.6\%) were male. Age average was 40.67 years $( \pm 9.12)$, which varied from 18 to 60 .

The number of family members (who now live together) ranged from 2 to 7 ; most of whom were married and lived with their families, and did not have chronic medical/psychological conditions. The distributions were as follows:

Table 2

Distribution of family members

\begin{tabular}{|lll|}
\hline Number of family members & Frequency & Percentage \\
\hline 2 & 5 & 3.6 \\
\hline 3 & 43 & 31.4 \\
\hline 4 & 60 & 43.8 \\
\hline 6 & 22 & 16.1 \\
\hline 7 & 4 & 2.9 \\
\hline
\end{tabular}


Table 3

Distribution of chronic medical/psychological conditions

\begin{tabular}{|llll|}
\hline Condition & Status & Frequency & Percentage \\
\hline \multirow{3}{*}{ Medical } & Currently diagnosed. & 19 & 13.9 \\
\cline { 2 - 4 } & Treated. & 2 & 1.5 \\
\cline { 2 - 4 } & No history. & 116 & 84.7 \\
& Currently diagnosed. & 4 & 2.9 \\
\cline { 2 - 4 } & Treated. & 2 & 1.5 \\
\cline { 2 - 4 } & No history. & 131 & 95.6 \\
\hline
\end{tabular}

Table 4

Distribution of chronic medical/psychological conditions

\begin{tabular}{|llll|}
\hline Condition & Status & Frequency & Percentage \\
\hline Medical & Currently diagnosed. & 19 & 13.9 \\
\cline { 2 - 4 } & Treated. & 2 & 1.5 \\
\cline { 2 - 4 } & No history. & 116 & 84.7 \\
\hline Psychiatric illness & Currently diagnosed. & 4 & 2.9 \\
\cline { 2 - 4 } & Treated. & 2 & 1.5 \\
\cline { 2 - 4 } & No history. & 131 & 95.6 \\
\hline
\end{tabular}

Also DASS-21 questionnaires results were gathered in this table.

Table 5

DASS-21 questionnaires results

\begin{tabular}{|lllllll|}
\hline & \multicolumn{2}{l}{ Depression Sub-Domain } & \multicolumn{3}{c|}{ Anxiety Sub-Domain } & Stress Sub-Domain \\
\hline Status & Frequency & Percentage & Frequency & Percentage & Frequency & Percentage \\
Normal & 71 & 51.8 & 63 & 46.0 & 60 & 43.8 \\
Mild & 14 & 10.2 & 11 & 8.0 & 17 & 12.4 \\
Moderate & 31 & 22.6 & 24 & 17.5 & 36 & 26.3 \\
Severe & 14 & 10.2 & 16 & 11.7 & 15 & 10.9 \\
Very Severe & 7 & 5.1 & 23 & 16.8 & 9 & 6.6 \\
\hline $\begin{array}{l}\text { Abnormal } \\
\text { Total }\end{array}$ & 66 & 48.2 & 74 & 54 & 77 & 56.2 \\
\hline
\end{tabular}


To test the parametric characteristics of our variables we used Kolmogorov-Smirnov test, which reported that only the family resilience score questionnaire had normal distribution $(P=0.2)$. To analyze the relationship between of qualitative variables, and depression, anxiety, and stress, Chi-square test was used.

Table 6

Chi-Square test of DASS-21 questionnaire with qualitative variables

\begin{tabular}{|c|c|c|c|c|c|c|}
\hline \multirow[b]{2}{*}{ Variable } & \multicolumn{2}{|c|}{$\begin{array}{l}\text { Depression Sub- } \\
\text { Domain }\end{array}$} & \multicolumn{2}{|c|}{ Anxiety Sub-Domain } & \multicolumn{2}{|c|}{ Stress Sub-Domain } \\
\hline & $\begin{array}{l}\text { Significant } \\
\text { Relevance }\end{array}$ & $\begin{array}{l}\mathrm{P} \\
\text { Value }\end{array}$ & $\begin{array}{l}\text { Significant } \\
\text { Relevance }\end{array}$ & $\begin{array}{l}\mathrm{P} \\
\text { Value }\end{array}$ & $\begin{array}{l}\text { Significant } \\
\text { Relevance }\end{array}$ & $\begin{array}{l}\mathrm{P} \\
\text { Value }\end{array}$ \\
\hline $\begin{array}{l}\text { Number of Family } \\
\text { Members }\end{array}$ & - & 0.248 & + & 0.016 & - & 0.181 \\
\hline Living Pattern & - & 0.447 & - & 0.629 & - & 0.648 \\
\hline Education Status & \pm & 0.085 & + & 0.002 & + & 0.011 \\
\hline Income & + & 0.041 & & 0.000 & + & 0.023 \\
\hline Medical Condition & - & 0.834 & - & 0.423 & - & 0.645 \\
\hline $\begin{array}{l}\text { Psychological } \\
\text { Condition }\end{array}$ & + & 0.000 & + & 0.000 & + & 0.000 \\
\hline Sex & \pm & 0.057 & - & 0.137 & + & 0.007 \\
\hline
\end{tabular}

In addition, both age and sex had no significant correlation with family resilience score according to Kendall's $(P=0.562)$, Spearman's test $(P=0.616)$, and Independent Sample t test $(P=0.701)$, respectively. Due to normal distribution of the family resilience score, One Way ANOVA test used to determine its relationship with qualitative variables. Analysis of variance is a set of statistical models that can investigate the difference between mean groups (more than three groups) and categories, so that these averages can be compared. Since in this test, if $P$ value is less than $0 / 05$ it is possible to find a significant relationship between variables, According to the results in the table, it seems that anxiety and depression were highly correlated with resiliency $(P=0 / 000)$, with mild to moderate resilience rates being higher among higher groups. 
Table 7

One Way ANOVA test of the family resilience score

\begin{tabular}{|c|c|c|}
\hline Variable & $\begin{array}{l}\text { Significant difference of average family resilience score among the } \\
\text { subgroups of variables }\end{array}$ & $\begin{array}{l}\mathrm{P} \\
\text { Value }\end{array}$ \\
\hline $\begin{array}{l}\text { Number of Family } \\
\text { Members }\end{array}$ & - & 0.495 \\
\hline Living Pattern & - & 0.118 \\
\hline Education Status & - & 0.431 \\
\hline Income & \pm & 0.078 \\
\hline Medical Condition & - & 0.415 \\
\hline $\begin{array}{l}\text { Psychological } \\
\text { Condition }\end{array}$ & - & 0.465 \\
\hline Sex & \pm & 0.000 \\
\hline Depression & + & 0.002 \\
\hline Anxiety & + & 0.000 \\
\hline Stress & + & 0.495 \\
\hline
\end{tabular}

\section{Discussion:}

As previously mentioned, this study was carried out to review, and assess Family Resilience's impact on depression, anxiety and stress. A total of 137 members of the families of autistic children were enrolled in our study, whose age mean were 40.67 years ( \pm 9.12). 80 female (58.4\%), and 57 male (41.6\%), most of whom had at least a bachelor degree (51.7\%), and generally were married and with living their families (78.8\%), with no chronic physical (84.7\%) or psychological (95.6\%) conditions. Mostly (42.3\%), they had approximate income of 10 to 30 million IRR. Based on data from the Statistical Center of Iran, average income of an urban household in the years of 2016 and 2017 was approximately 37 million IRR in Tehran[16], Given the current economic conditions of Iran in 2018 the average income of our study members is considered as below-average, and low income.

Regarding their psychological status, $48.2 \%$ had depression (mild to severe), $54 \%$ had anxiety, and $56.2 \%$ had stress, which is much higher rates than normal population of Tehran according to Nazari's study[18]. Income, psychological conditions, educational degree, and gender were risk factors for both depression and stress. Also Altemus stated that gender is an important factor for depression, so that the probability of this disorder in women is higher and in the event of illness they show more severe symptoms from the onset[19]. Nevertheless, Nazari's results were corroborative with ours regarding to educational status effect[18]. Number of family members, educational degree, income, and psychological conditions had a significant effect on people's anxiety. Other studies such as Mcleen's et al., and Altemus's et al. observed that the ratio of male/female in all of the anxiety disorders were not close to each other, which violates 
the current study results[19,20]. In addition, Verma's study stated that stress and stress response differ between men and women[20]. In the study of the prevalence of psychiatric disorders in Iran, conducted by Sharifi et al., anxiety disorders were the most prevalent disorder with $15.6 \%$ frequency[22], Which is much less than our samples statistics. Sareen et al. also reported that low income or a reduction in income can directly lead to mental disorders, such as depression and anxiety[23].

Furthermore, our findings showed that family resiliency average score was $193( \pm 25)$. There was no significant correlation with either age or gender. Which is in contrast with Kavaliotis study, indicating that sex has a different relation to the family resilience levels, as the men show lower scores in comparison with women[24]. But depression, anxiety and stress were related to the level of resilience, in a way which normal groups got higher scores than abnormal groups. It appears that having more powerful resilience ability contributes to lower depression, anxiety and stress levels. In confirmation, Abir's et al. study found that ASD children parents who have the resiliency indices are able to be solving problems associated with child care better than the others[25]. In this regard Plumb et al. results showed that families of ASD children experience high levels of stress. But resilient families had lower levels[26]. Plus, another study noted resilience as a preventive factor to depression and also to bitter experiences[27].

Finally, one limitation in this research was limited accessibility to sample family members. Nevertheless the measurements of the variables were based on self-assessment, which makes it less controlled and standardized. We propose the use of different kind of assessment such as interview for future studies. In addition, this study recommends that future curricula should be designed to increase the level of resilience of individuals, and have a before-after training tests for depression, anxiety and stress status to determine their changes. It is also essential to assess family functioning as for resilience increase.

\section{Conclusion:}

From the results of this study, we can conclude that family resilience is one of the important factors that directly affects the level of depression, anxiety and stress among the family members of the autistic children. Therefore it is recommended to meliorate this ability in family members by various means such as training, counseling, support groups, and etc.

\section{Declarations}

\section{Aknowledgment:}

The authors thank Ms. Fahimeh Mousavinejad, Director of Aeen Mehrvarzi Elementary School, for her cooperation in data gathering from the parents of children with autism.

\section{Author Contributions:}

$\mathrm{MAH}$ and $\mathrm{FH}$ designed the study, conducted the review and performed the data analysis. $\mathrm{FSH}$, and MAA assisted in the study design and data analysis. FH, and FSH interpreted the data and drafted the 
manuscript. All authors read and approved the final manuscript before submission

\section{Founding:}

This research received no specific grant from any funding agency in the public, commercial, or not-forprofit sectors and in the design of the study and collection, analysis, and interpretation of data and in writing the manuscript there is no role for any funding body.

\section{Availability of data and materials:}

All data and material are available at the Department of Psychiatry, Faculty of Medicine, Iran University of Medical Sciences

\section{Ethics approval and consent to participate:}

The study was approved by the Ethics Committee of the Iran University Medical Sciences under number IR.IUMS.REC.1397.110. All participants (members of the families of children with autism) were informed about the study and only those providing written informed consent were enrolled in the study.

\section{Consent for publication :}

Not applicable

\section{Competing interests:}

The authors declare that they have no competing interests

\section{References}

1. Waller MA, Okamoto SK. Resiliency factors related to substance use/resistance: Perceptions of Native adolescents of the Southwest. J. Soc. \& Soc. Welfare. 2003;30:79.

2. Resnick MD. Resilience and protective factors in the lives of adolescents. Journal of Adolescent Health. 2000 Jul 1;27(1):1-2.

3. Walsh F. The Guilford family therapy series.(1998)

4. Walsh F. Family resilience: A framework for clinical practice. Family process. 2003 Mar;42(1):1-8.

5. Walsh F. Strengthening family resilience. Guilford publications; 2015 Sep $28 .$.

6. Anagnostou E. Clinical trials in autism spectrum disorder: evidence, challenges and future directions. Current opinion in neurology. 2018 Apr 1;31(2):119-25.

7. Bell V, Dunne H, Zacharia T, Brooker K, Shergill S. A symptom-based approach to treatment of psychosis in autism spectrum disorder. BJPsych open. 2018 Jan;4(1):1-4.

8. Levaot Y, Meiri G, Dinstein I, Menashe I, Shoham-Vardi I. Autism prevalence and severity in BedouinArab and Jewish communities in southern Israel. Community mental health journal. 2019 Jan 
31;55(1):156-60.

9. Osborne LA, Reed P. Stress and self-perceived parenting behaviors of parents of children with autistic spectrum conditions. Research in Autism Spectrum Disorders. 2010 Jul 1;4(3):405-14.

10. Eisenhower AS, Baker BL, Blacher J. Preschool children with intellectual disability: syndrome specificity, behaviour problems, and maternal well-being. Journal of intellectual disability research. 2005 Sep;49(9):657-71.

11. Tu MT, Grunau RE, Petrie-Thomas J, Haley DW, Weinberg J, Whitfield MF. Maternal stress and behavior modulate relationships between neonatal stress, attention, and basal cortisol at 8 months in preterm infants. Developmental Psychobiology. 2007 Mar;49(2):150-64. .

12. Abidin RR. Introduction to the special issue: The stresses of parenting. Journal of clinical child psychology. 1990 Dec 1;19(4):298-301.

13. Kazdin AE, Whitley MK. Treatment of parental stress to enhance therapeutic change among children referred for aggressive and antisocial behavior. Journal of consulting and clinical psychology. 2003 Jun;71(3):504.

14. Sixbey MT. Development of the family resilience assessment scale to identify family resilience constructs. University of Florida; 2005.

15. Dadashi Haji M, Karaminia R, Salimi SH, Ahmadi Tahour M. Translation and Validation of the "Walsh Family Resilience Questionnaire” for Iranian Families. International Journal of Behavioral Sciences. 2018 Aug 1;12(2):48-52.

16. Asghari A, Saed F, Dibajnia P. Psychometric properties of the Depression Anxiety Stress Scales-21 (DASS-21) in a non-clinical Iranian sample. Int J Psychol. 2008;2(2):82-102.

17. Ebrahimi A, Aarabi S, Khaluei MM. Comparing the Mental Health and Some Positive Psychologic Factors Including Happiness, Hope and Spirituality among Students of Medicine in Isfahan University of Medical Sciences, Iran, during Years of Education. Journal of Isfahan Medical School. 2014 Jan 15;31(261).

18. Nazari H, Hormozi K, Mashayekhi F, Valizadeh M, Falahati F. Prevalence of depression in Tehran. (2002)

19. Altemus M, Sarvaiya N, Neill Epperson C. Sex differences in anxiety and depression clinical perspectives:Front Neuroendocrinol. 2014 Aug;35(3):320-30.

20. McLean CP, Asnaani A, Litz BT, Hofmann SG. Gender differences in anxiety disorders: prevalence, course of illness, comorbidity and burden of illness. Journal of psychiatric research. 2011 Aug 1;45(8):1027-35.

21. Verma R, Balhara YP, Gupta CS. Gender differences in stress response: Role of developmental and biological determinants. Industrial psychiatry journal. 2011 Jan;20(1):4.

22. Sharifi V, Amin-Esmaeili M, Hajebi A, Motevalian A, Radgoodarzi R, Hefazi M, Rahimi-Movaghar A. Twelve-month prevalence and correlates of psychiatric disorders in Iran: the Iranian Mental Health Survey, 2011. Arch Iran Med. 2015 Feb;18(2):76-84. 
23. Sareen J, Afifi TO, McMillan KA, Asmundson GJ. Relationship between household income and mental disorders: findings from a population-based longitudinal study. Archives of general psychiatry. 2011 Apr 4;68(4):419-27.

24. Kavaliotis $P$. The Importance of the Sex of the Parents and of the Sex and Age of the Children with Autism Spectrum Disorders to Family Resilience. Journal of Educational and Developmental Psychology. 2017;7(1).

25. Bekhet AK, Johnson NL, Zauszniewski JA. Resilience in family members of persons with autism spectrum disorder: A review of the literature. Issues in mental health nursing. 2012 Oct 3;33(10):6506.

26. Bodaghi, E., Alipour, F., Bodaghi, M., Nori, R., Peiman, N., Saeidpour, S. The Role of Spirituality and Social Support in Pregnant Women's Anxiety, Depression and Stress Symptoms. Community Health Journal, 2017; 10(2): 72-82.

27. Edward KL. Resilience: A protector from depression. Journal of the American psychiatric nurses association. 2005 Aug;11(4):241-3. 